\title{
A Chinese Chan-based mind-body intervention improves psychological well-being and physical health of community-dwelling elderly: a pilot study
}

This article was published in the following Dove Press journal:

Clinical Interventions in Aging

23 April 2014

Number of times this article has been viewed

\author{
Ruby Yu' \\ Jean Woo' \\ Agnes S Chan ${ }^{2-4}$ \\ Sophia L Sze $e^{2,3}$
}

'Department of Medicine and Therapeutics, ${ }^{2}$ Department of Psychology, ${ }^{3}$ Chanwuyi Research Center for Neuropsychological Well-Being, The Chinese University of Hong Kong, New Territories, Hong Kong; ${ }^{4}$ Henan Songshan Research Institute for Chanwuyi, Henan, People's Republic of China

Correspondence: Ruby Yu Department of Medicine and Therapeutics, The Chinese University of Hong Kong, I0/F, Clinical Sciences Building, Prince of Wales Hospital, Shatin, New Territories, Hong Kong Tel +85226322190

Fax +852 26379215

Email rubyyu@cuhk.edu.hk
Background: The aim of this study was to explore the potential benefits of the Dejian mind-body intervention (DMBI) for psychological and physical health in older Chinese adults.

Methods: After confirmation of eligibility, the subjects were invited to receive DMBI once a week for 12 weeks. The intervention involved components of learning self-awareness and selfcontrol, practicing mind-body exercises, and adopting a special vegetarian diet. Interventionrelated changes were measured using the Perceived Stress Scale, Geriatric Depression Scale, Pittsburgh Sleep Quality Index, Chinese Constipation Questionnaire, and self-report ratings of health. Indicators of metabolic syndrome and walking speed were also measured.

Results: Of the 44 subjects recruited, 42 (54.8\% men) completed the study, giving an adherence rate of $95 \%$. There was a significant reduction in perceived stress $(P<0.05)$. A significant improvement was also found in systolic blood pressure among those who had abnormally high blood pressure at baseline $(P<0.05)$. Physical fitness as reflected by walking speed was also significantly increased after the intervention $(P<0.05)$. Sleep disturbances were reduced $(P<0.01)$. Self-rated health was significantly enhanced, with the percentage rating very good health increasing from $14.3 \%$ at baseline to $42.8 \%$ after the intervention $(P<0.001)$. No intervention effect was found for waist circumference, lipids and fasting blood glucose levels, Pittsburgh Sleep Quality Index global score, and constipation measures.

Conclusion: The DMBI was feasible and acceptable, and subjects showed some improvements in psychological and physical health. A larger controlled trial is needed to confirm these promising preliminary results.

Keywords: mind-body intervention, Chan practice, psychological stress, physical fitness, self-rated health, elderly

\section{Introduction}

With population aging, the number of people with chronic diseases and psychological problems is expected to increase. Sleep problems, constipation, psychological distress, low mood, low energy, and obesity-related disorders, such as diabetes and metabolic syndrome, are common in the elderly, with varying impact on physical and psychological function. ${ }^{1-4}$ The world's population is aging so rapidly that the population aged 60 years and older has nearly doubled during the past two decades and is projected to reach 2 billion by $2050 .{ }^{5}$ Therefore, the growing number of elderly people highlights a need to identify interventions and strategies to maintain and enhance their health.

Previous studies have demonstrated the therapeutic effects of mind-body intervention (such as tai chi, qigong, yoga, and meditation) in both clinical and normal 
populations. ${ }^{6-9}$ Common features of these interventions are breathing and mindfulness, both of which stem from the Buddhist tradition. Among the mind-body interventions available for the elderly, tai chi has been the most studied. The findings from meta-analyses of tai chi with regard to enhancing musculoskeletal strength (ie, improving balance, muscle strength, flexibility, and reducing the risk of falls) are comparatively robust and promising. ${ }^{10}$ However, its positive effects on other physical (eg, blood pressure [BP]) and psychological (eg, depressive mood) aspects remain inconclusive. ${ }^{11,12}$ In sum, this line of research is still in its infancy, and there have been relatively few studies in elderly populations, and the results regarding therapeutic effects are mixed. ${ }^{10-13}$

The Dejian mind-body intervention (DMBI) is a traditional Chinese Chan (Zen)-based mind-body intervention, which was developed upon the medical principle of the Shaolin temple. ${ }^{14}$ It consists of four interconnected components: Chan practice (self-awareness and enhancement/ psychosocial education); mind-body exercises (including training in Dan Tian breathing, shoulder relaxation, and nasal massage); dietary modification; and clearing of the bodily orifices, which aims to improve physical and psychological health. Clinical observations have demonstrated the promising effects of DMBI on common physical and psychological problems in middle-aged and older adults. A randomized controlled trial found that four 90-minute sessions of DMBI significantly improved bowel function, neurophysiological status, and depressed mood in community-dwelling adults aged 25-64 years to a greater extent than conventional psychological intervention. ${ }^{15}$ A further two studies have suggested the positive effects of ten sessions of DMBI on mood, gastrointestinal symptoms, and insomnia problems in patients aged 28-62 years with depression. ${ }^{16,17}$ Even severe cases, such as a 22 -year-old chronic epileptic male ${ }^{18}$ and a 9-year-old boy with autism, ${ }^{19}$ were able to master and apply some of the techniques of DMBI with the assistance of their caregivers, and showed substantial enhancement of cognitive function (eg, improvement from severely to moderately impaired memory and executive functions to within normal limits after 8 months of training) and physical health (eg, reduced frequency of sickness).

Most of our previous studies of DMBI have primarily examined its beneficial effects in younger and middle-aged populations. ${ }^{15-19}$ The potential benefits of DMBI for older people have not yet been systematically examined. In light of encouraging clinical observations and positive feedback from some older people who have practiced DMBI (eg, better gastrointestinal health, less depressive mood), the DMBI seems to be well accepted and practical for the elderly population. Given that DMBI is a holistic medical approach to healing the mind and body through cultivating positive thinking and attitude, as well as adopting a healthy lifestyle, it is likely to have some positive effects on physical and psychological wellness in older adults. Therefore, we conducted the present study to explore this issue.

\section{Materials and methods Subjects}

Forty-four community-dwelling Chinese men and women aged 60-83 years were recruited for the study between October 2012 and January 2013. Recruitment was done by placing notices in six community health and social centers in the New Territories East regions in Hong Kong and by Internet publicity (including emails, advertisement, and discussion forums). Individuals with a history of head injury or a neurological/psychiatric disorder, an inability to walk, or present severe illness were excluded.

\section{Procedure}

The study had a pre-post pilot design. All eligible subjects participated voluntarily and their informed consent was obtained prior to the study. Each subject was individually assessed by research assistants, who were blinded to the experimental design and the potential effects of the intervention, their demographic information (such as marital status, education level, occupation), medical history, current use of medications, clinical and lifestyle factors, and physical performance before and after the intervention. After the baseline assessment, the subjects were invited to attend group training in Chinese Chan-based DMBI for 12 weekly 90-minute sessions. They were also asked to keep a diary recording their home-based practice during the intervention. The study was conducted in accordance with the Declaration of Helsinki, and the research protocol was approved by the Joint Chinese University of Hong Kong-New Territories East Cluster Clinical Research Ethics Committee.

\section{Intervention}

DMBI is based on the Chinese Chan tradition known as Chanwuyi (ie, Zen, martial arts, and healing). The intervention is named DMBI for the grand master of Chanwuyi (Shi Dejian, a Shaolin monk). The aims of DMBI, which emphasizes integration of mind and body, are to enhance mental and physical health by changing daily dietary and exercise habits and to alleviate stressful responses by understanding the root of problems in accordance with Buddhist philosophy. 
The intervention was conducted by a clinical psychologist with more than 10 years of clinical experience in running group therapy and familiar with the DMBI model. Throughout the 12 training sessions, subjects were taught the fundamental principles and techniques of DMBI, and their progress was closely monitored by the trainer. Three specific components were included:

1. Chan practice, where subjects were guided on how to increase their awareness of how unrealistic desires, eg, greed (ie, craving for something or somebody beyond reality), anger, and obsession may affect their mental and physical health, to increase their sensitivity to associated physical signs (eg, headaches, shortness of breath, insomnia), and to modify their thought processes and thereby alleviate negative thoughts.

2. Mind-body exercises, where subjects were taught basic traditional Shaolin mind-body techniques, including training in Dan Tian breathing. Subjects put their hands gently on the Dan Tian (about half an inch below the navel) while breathing in and out naturally. They were taught to contemplate the Dan Tian region during inhalation and the nose during exhalation. Subjects were also instructed on how to relax their shoulders and to massage both sides of the nasal bridge to facilitate normal breathing through the nostrils. The purpose of these exercises is to reduce stress, enhance strength and flexibility of all four limbs, and to improve overall physical health and circulation of $Q i$ and blood. The duration of practice was not fixed, and subjects were instructed to practice the exercises until they felt warm and relaxed.

3. Dietary modification, where subjects were encouraged to adopt a vegetarian diet and to refrain from hot and spicy food (eg, ginger, garlic, green onion) that would generate excessive internal heat according to the Chan principle and adversely affect their mood and physical health. They were also advised to consume fresh vegetables, fruit, grains, beans, mushrooms, nuts, and root vegetables.

\section{Measurements}

\section{Physical health}

With the subject seated, a 21-gauge multisample needle (Vacutte ${ }^{\circledR}$, Greiner Bio-One International AG, Kremsmuenster, Austria) was used to perform a minimally traumatic venepuncture before noon after 12 hours of fasting. Fasting $7 \mathrm{~mL}$ blood samples were used for analysis of triglyceride, high-density lipoprotein cholesterol, and blood glucose levels. Blood measurements were conducted at the Prince of
Wales Hospital Chemical Pathology Laboratory (accredited by the National Association of Testing Authorities). All blood measurements were analyzed in a blinded manner.

Systolic and diastolic BP was measured using a HEM7011 monitor (Omron Healthcare Europe BV, Nijmegen, the Netherlands), with the subject having been seated quietly for at least 5 minutes. The average of two readings was recorded. Standing height was measured to the nearest $0.5 \mathrm{~cm}$ with the subject in bare feet, standing back against a wall, and eyes looking straight ahead. Weight was measured using beam balance scales with the subject in light clothing. Body mass index was documented. Waist circumference was measured to the nearest $\mathrm{cm}$ over the abdomen at the shortest diameter between the costal margin and iliac crest, using a standard tape measure.

Cardiorespiratory (physical) fitness was measured by the 6-minute walk test. This test reflects the ability of subjects to perform physical activities of daily living and records the distance that subjects can walk in 6 minutes. ${ }^{20}$ Subjects were instructed to walk back and forth along an 18-meter corridor. The average walking speed was calculated by dividing the distance by time. We used this measure as an indicator of physical fitness because it is easier to incorporate into large cohort studies, compared with maximal oxygen uptake $\left(\mathrm{VO}_{2 \max }\right)$ on treadmill or bicycle exercises. Our preliminary data have suggested that it correlates well with $\mathrm{VO}_{2 \max }(r=0.43, P<0.001),{ }^{21}$ in a manner comparable with other studies. ${ }^{22}$

Sleep quality was assessed using the Chinese version of the Pittsburgh Sleep Quality Index (PSQI). ${ }^{23,24}$ The PSQI comprises 18 questions and discriminates "poor" from "good" sleep quality by measuring seven dimensions, including subjective sleep quality, sleep latency, sleep duration, habitual sleep efficiency, sleep disturbances, use of sleep medications, and daytime dysfunction during the previous month. Scoring of answers is based on a 4-point Likert scale ( 0 to 3 ), where 3 reflects the negative extreme. A global score $\geq 5$ indicates poor sleep quality. Numerous studies using the PSQI in a variety of older adult populations have supported its high validity and reliability. ${ }^{25,26}$ The Chinese version of the PSQI has been successfully used in the Chinese population. ${ }^{27,28}$

Constipation was assessed using the 6-item version of the Chinese Constipation Questionnaire (CCQ), ${ }^{29}$ a self-report measure designed to diagnose functional constipation in the Chinese population. The CCQ measures bowel function, stool and rectal symptoms, and abdominal symptoms in the preceding 2 weeks using a 5-point Likert scale (0, asymptomatic; 
4 , very severe symptoms). An additional question addresses the use of laxatives. A score $\geq 5$ is used to discriminate between constipated and nonconstipated individuals.

\section{Psychological health}

Perceived stress was assessed using the Chinese version of the Perceived Stress Scale (PSS). ${ }^{30,31}$ This scale measures the degree to which individuals perceive their daily life as having been stressful during the previous month using a 5-point Likert scale ( 0 , never; 4 , very often). Total scores can range from 0 to 40, with higher scores indicating higher levels of perceived stress.

Depressive symptoms were assessed using the Chinese version of the Geriatric Depression Scale (GDS)-Short Form. ${ }^{32,33}$ This self-rated 15-item scale measures the degree of depressive mood symptoms during the previous week in elderly individuals using a "yes/no" response. The total score can range from 0 to 15 , with higher scores indicating higher levels of depressive mood symptoms.

\section{Self-rated health}

Self-rated health was elicited by a single question, "Generally speaking, how is your health: very good, good, fair, poor, or very poor?"

\section{Data analysis}

Differences between baseline and post-intervention were compared using paired $t$-tests for continuous variables and McNemar's tests for categorical variables. The effect size in terms of the Cohen's $d$ statistic was also calculated. In addition, the intervention effect was examined by computing the reliable change index, ${ }^{34}$ which is a statistical computation used to determine if a clinically significant change is reliable, and is calculated by dividing the prepost difference score by the standard error of difference between the two test scores. As proposed by Wise, ${ }^{35}$ a reliable change can be reflected by a reliable change index above 0.84 . To evaluate whether the effect of DMBI was more pronounced in subjects with higher stress levels than in those with lower stress levels, the subjects were divided into tertiles (lower, moderate, and higher) according to their baseline PSS scores for further analysis by paired $t$-tests. The analyses were also repeated for walking speed. To examine the changes in BP levels from baseline to post-intervention, subjects were classified into five BP groups according to the guidelines of the American Heart Association $^{36}$ as follows:
- Normal (systolic $<120 \mathrm{mmHg}$ and diastolic $<80 \mathrm{mmHg}$ )

- Prehypertension (systolic 120-139 mmHg or diastolic 80-89 mmHg)

- High BP, stage 1 (systolic 140-159 mmHg or diastolic 90-99 mmHg)

- High BP, stage 2 (systolic 160-179 mmHg or diastolic 100-109 mmHg)

- Hypertensive crisis (systolic $\geq 180 \mathrm{mmHg}$ or diastolic $\geq 110 \mathrm{mmHg}$ )

Subjects showing a change from prehypertension to normal BP or from a more impaired to a less impaired level (eg, from hypertensive crisis to high BP, stage 1) were considered to be "improved", and vice versa as "declined" for analysis using Wilcoxon signed-rank tests. In fact, classification of BP is somewhat arbitrary, and there is uncertainty regarding the optimal cutoff values for defining hypertension in the elderly population. The latest guidelines for the management of hypertension raise the threshold for treatment of BP in people aged 60 years and older, ${ }^{37}$ as has another previous study. ${ }^{38}$ With regard to the acceptability of the intervention, qualitative feedback from the subjects was also analyzed. All analyses were carried out using Windows-based Statistical Package for the Social Sciences version 17.0 software (SPSS, Chicago, IL, USA). $P$-values $<0.05$ were considered to be statistically significant.

\section{Results}

\section{Baseline characteristics}

Forty-two older Chinese adults (23 men and 19 women) of mean age $65.9 \pm 4.9$ (range 60.1-83.7) years were examined. Most of the subjects were married (73.8\%), had secondary education $(88.1 \%)$, and were retired $(71.4 \%)$. Baseline data showed that $16(38.1 \%)$ subjects had a previous history of hypertension, $11.9 \%$ had diabetes, and $4.8 \%$ had chronic obstructive pulmonary disease (Table 1).

\section{Changes in indicators of psychological health}

Mean changes in PSS and GDS scores from baseline to postintervention are shown in Table 2. There was a significant reduction in PSS score (baseline, 7.81; post-intervention, 6.19; mean difference $-1.62, P<0.05)$ and a marginally significant reduction in GDS score $(P=0.07)$. This marginal improvement was expected given that the subjects were not clinically depressed at baseline. In addition, subjects in the highest tertile for PSS score at baseline demonstrated 
greater reduction after the intervention (baseline, 13.94; post-intervention, 9.28; mean difference $-4.67, P<0.01$, see Figure 1).

\section{Changes in indicators of physical health}

Mean changes in indicators of metabolic syndrome from baseline to post-intervention are shown in Table 2. Although there were no significant changes in waist circumference, lipid levels, BP, or fasting blood glucose at a group level, those with high baseline BP showed significant improvement (baseline systolic $156.25 \mathrm{mmHg}$; post-intervention systolic $150.04 \mathrm{mmHg}$; mean difference $-6.21 \mathrm{mmHg}, P<0.05$, data not shown). In addition, when subjects were classified as either "improved" (eg, from prehypertension to a normal level), "no change", or "declined" (eg, from prehypertension to high BP, stage 1), it was found that 12 (28.6\%) demonstrated an improvement in BP, which was significantly more than the proportion of subjects classified as "declined" $(16.7 \% ; Z=-1.67$, $P<0.05)$. Further analyses were performed in subjects who had abnormal BP (ie, high blood pressure stage 1 through to hypertensive crisis) before intervention. It was found that improvement was more pronounced in this group, with a

Table I Baseline characteristics $(n=42)$

\begin{tabular}{|c|c|}
\hline & n (\%) \\
\hline \multicolumn{2}{|l|}{ Age group, years } \\
\hline $60-69$ & $37(88.1)$ \\
\hline $70-79$ & $4(9.5)$ \\
\hline $80+$ & I (2.4) \\
\hline \multicolumn{2}{|l|}{ Sex } \\
\hline Men & $23(54.8)$ \\
\hline Women & $19(45.2)$ \\
\hline \multicolumn{2}{|l|}{ Marital status } \\
\hline Married & $31(73.8)$ \\
\hline \multicolumn{2}{|l|}{ Education } \\
\hline Primary and below & 5 (II.9) \\
\hline Secondary & $26(61.9)$ \\
\hline Tertiary and above & II (26.2) \\
\hline \multicolumn{2}{|l|}{ Occupation } \\
\hline Retired & $30(7 I .4)$ \\
\hline \multicolumn{2}{|c|}{ Medical history of chronic disease } \\
\hline Hypertension & $16(38.1)$ \\
\hline Diabetes & 5 (II.9) \\
\hline COPD & $2(4.8)$ \\
\hline Heart disease & $\mathrm{I}(2.4)$ \\
\hline Stroke & I (2.4) \\
\hline \multicolumn{2}{|l|}{ Medications } \\
\hline Antihypertensive drugs & $14(33.3)$ \\
\hline Lipid-lowering drugs & $13(31.0)$ \\
\hline Antidiabetic drugs & $5(11.9)$ \\
\hline COPD drugs & $2(4.8)$ \\
\hline Current smoking & I (2.4) \\
\hline
\end{tabular}

Abbreviation: COPD, chronic obstructive pulmonary disease. significantly higher proportion of subjects demonstrating improved BP $(\mathrm{n}=12,42.9 \%)$ than those with declined BP ( $\mathrm{n}=3,10.7 \%, Z=-2.50, P<0.05$, data not shown).

Mean changes in walking speed, PSQI global score and subscores, and CCQ score from baseline to post-intervention are shown in Table 2. A significant improvement was found for walking speed (baseline, $1.39 \mathrm{~m} / \mathrm{s}$; post-intervention, $1.43 \mathrm{~m} / \mathrm{s}$; mean difference $0.04 \mathrm{~m} / \mathrm{s}, P<0.05$ ). In addition, subjects in the lowest tertile for walking speed at baseline demonstrated greater improvement after the intervention (baseline, $1.20 \mathrm{~m} / \mathrm{s}$; post-intervention, $1.28 \mathrm{~m} / \mathrm{s}$; mean difference $0.08 \mathrm{~m} / \mathrm{s}, P<0.05$, Figure 2). Sleep disturbances were significantly reduced (baseline, 0.95; post-intervention, 0.64 ; mean difference -0.31 , $P<0.01)$; however, habitual sleep efficiency was also reduced, but to a lesser degree $(P<0.05)$. No significant change was found for PSQI global scores or CCQ scores.

\section{Changes in self-rated health}

Mean changes in self-rated health from baseline to postintervention are shown in Table 2. Self-rated health was significantly improved (baseline, 3.19; post-intervention, 2.81; mean difference $-0.38, P<0.001)$. Results of the McNemar's test also showed significant enhancement from baseline (very good health, $14.3 \%$ ) to post-intervention (very good health, $42.9 \%, P<0.001$, Table 3 ).

\section{Adherence with DMBI}

The adherence rate was $95 \%$ and the mean attendance rate was $93 \%$. According to the log records for practice at home, 25 subjects $(60 \%)$ have abstained from or reduced their intake of "not recommended" foods, and 34 (81\%) had consumed at least three "recommended" food categories every day. Regarding mind-body exercises, 40 (95\%) practiced this at home for an average of about 25 minutes per day. Group sharing and evaluation was also done after the intervention, and $36 \%$ of subjects reported that they had significant treatmentrelated improvement in their bowel/digestive problems. Further, all subjects reported that they enjoyed the intervention, and that they were satisfied with its content.

\section{Discussion}

Our findings suggest that a 12 -week DMBI approach is safe, feasible, and enjoyable for community-dwelling older adults. In addition, subjects who participated in the DMBI program showed improvements in psychological well-being, BP, physical performance, and self-rated health. These results indicate that while DMBI has much potential for improving psychological 
Table 2 Changes in indicators of psychological and physical health

\begin{tabular}{|c|c|c|c|c|c|c|}
\hline & $\begin{array}{l}\text { Baseline } \\
\text { Mean } \pm \text { SD }\end{array}$ & $\begin{array}{l}\text { Post-intervention } \\
\text { Mean } \pm \text { SD }\end{array}$ & $\begin{array}{l}\text { Mean difference } \\
\text { Mean } \pm \text { SD }\end{array}$ & $\begin{array}{l}P \text {-value } \\
\text { (paired } t \text {-test) }\end{array}$ & $\mathbf{R C l}$ & $\begin{array}{l}\text { Effect } \\
\text { size }\end{array}$ \\
\hline \multicolumn{7}{|l|}{ Indicators of psychological health } \\
\hline PSS, score & $7.8 I \pm 6.55$ & $6.19 \pm 4.84$ & $-1.62 \pm 4.89$ & 0.038 & 2.14 & $0.33^{+}$ \\
\hline GDS, score & $2.29 \pm 2.51$ & $1.64 \pm 2.12$ & $-0.64 \pm 2.24$ & 0.070 & 1.86 & 0.29 \\
\hline \multicolumn{7}{|l|}{ Indicators of physical health } \\
\hline Waist circumference, $\mathrm{cm}$ & $76.26 \pm 7.46$ & $77.50 \pm 7.67$ & $0.32 \pm 2.44$ & 0.399 & 0.85 & 0.13 \\
\hline Triglycerides, mmol/L & $1.29 \pm 0.60$ & I. $34 \pm 0.87$ & $0.05 \pm 0.49$ & 0.508 & 0.67 & 0.10 \\
\hline $\mathrm{HDL}$ cholesterol, mmol/L & $1.54 \pm 0.39$ & $1.57 \pm 0.46$ & $0.04 \pm 0.19$ & 0.192 & 1.33 & 0.20 \\
\hline Systolic blood pressure, $\mathrm{mmHg}$ & $|45.37 \pm| 8.72$ & $142.94 \pm 16.42$ & $-2.43 \pm 14.35$ & 0.279 & 1.10 & 0.17 \\
\hline Diastolic blood pressure, $\mathrm{mmHg}$ & $81.00 \pm 10.57$ & $81.35 \pm 8.99$ & $0.35 \pm 7.76$ & 0.774 & 0.29 & 0.04 \\
\hline Fasting blood glucose, $\mathrm{mmol} / \mathrm{L}$ & $5.36 \pm 0.95$ & $5.46 \pm 0.94$ & $0.09 \pm 0.56$ & 0.302 & 1.04 & 0.16 \\
\hline Walking speed, $\mathrm{m} / \mathrm{s}$ & $1.39 \pm 0.17$ & $1.43 \pm 0.17$ & $0.04 \pm 0.12$ & 0.028 & 2.28 & $0.35^{+}$ \\
\hline PSQI, global score & $5.38 \pm 3.62$ & $5.36 \pm 3.39$ & $-0.02 \pm 2.64$ & 0.954 & 0.06 & 0.01 \\
\hline Subjective sleep quality, subscore & $1.00 \pm 0.70$ & $0.90 \pm 0.62$ & $-0.10 \pm 0.58$ & 0.290 & 1.07 & 0.16 \\
\hline Sleep latency, subscore & $0.64 \pm 0.82$ & $0.64 \pm 0.91$ & $0.00 \pm 0.10$ & 1.000 & 0.00 & 0.00 \\
\hline Sleep duration, subscore & $1.57 \pm 1.02$ & $1.69 \pm 1.00$ & $0.12 \pm 0.91$ & 0.405 & 0.84 & 0.13 \\
\hline Habitual sleep efficiency, subscore & $0.88 \pm 1.23$ & $1.26 \pm 1.15$ & $0.38 \pm 1.13$ & 0.034 & 2.19 & $0.34^{+}$ \\
\hline Sleep disturbances, subscore & $0.95 \pm 0.58$ & $0.64 \pm 0.58$ & $-0.31 \pm 0.56$ & 0.001 & 3.57 & $0.55^{+}$ \\
\hline Use of sleeping medication, subscore & $0.07 \pm 0.46$ & $0.10 \pm 0.48$ & $0.02 \pm 0.68$ & 0.822 & 0.23 & 0.04 \\
\hline Daytime dysfunction, subscore & $0.24 \pm 0.58$ & $0.14 \pm 0.42$ & $-0.10 \pm 0.73$ & 0.400 & 0.85 & 0.13 \\
\hline CCQ, score & $0.79 \pm 1.26$ & $0.64 \pm 0.96$ & $-0.14 \pm 1.07$ & 0.393 & 0.86 & 0.13 \\
\hline \multicolumn{7}{|l|}{ Indicator of perceived health } \\
\hline Self-rated health, score & $3.19 \pm 0.67$ & $2.81 \pm 0.92$ & $-0.38 \pm 0.62$ & $<0.001$ & 3.97 & $0.6 \mathrm{I}^{++}$ \\
\hline
\end{tabular}

Notes: ${ }^{+}$Small effect size; +"medium effect size.

Abbreviations: RCl, reliable change index; PSS, Perceived Stress Scale; GDS, Geriatric Depression Scale; HDL, high-density lipoprotein; PSQI, Pittsburgh Sleep Quality Index; CCQ, Chinese constipation questionnaire; SD, standard deviation.

health, it also has therapeutic effects on physical health and enhances self-rated health in older Chinese adults.

As people age, associated medical problems and disability may cause excessive stress, which can influence a variety of health conditions. Scientific research has demonstrated the benefits of mind-body interventions, including mindfulness meditation $^{39}$ and yoga, ${ }^{40}$ with regard to stress, mood, and well-being. Based on traditional Chinese Shaolin medical practice, DMBI as a holistic intervention approach to the health of mind and body also showed beneficial effects on perceived psychological stress in the present study. Throughout the psychosocial education process, subjects were guided using Chinese Chan principles on how to alter their negative thoughts in accordance with Buddhist philosophy and how these changes would affect their mental and physical health, so as to facilitate the development of positive thinking and a realistic perspective of the world. This intervention could also help to change the ways in which people deal with problems

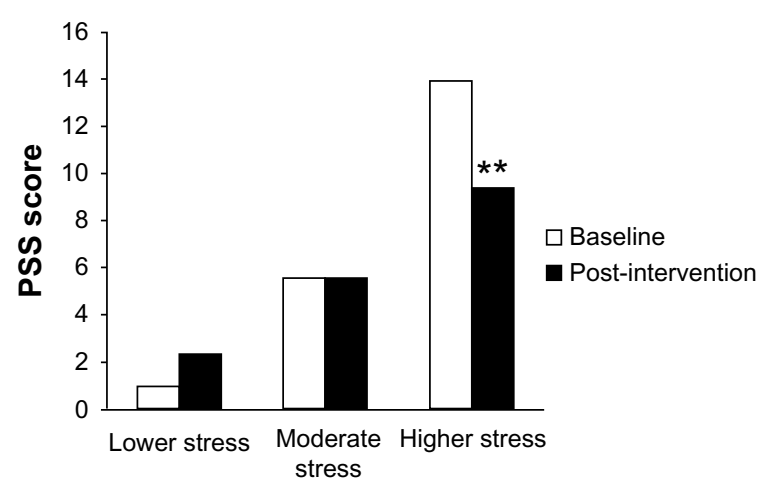

Figure I Change in perceived stress levels. Note: $* * P<0.01$.

Abbreviation: PSS, Perceived Stress Scale.

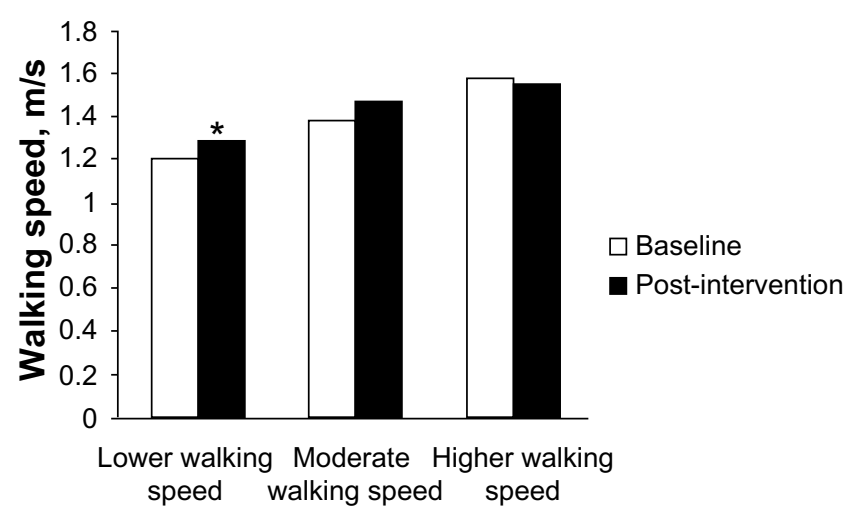

Figure 2 Change in walking speed. Note: $* p<0.05$. 
Table 3 Changes in self-rated health

\begin{tabular}{llll}
\hline & $\begin{array}{l}\text { Baseline } \\
\mathbf{n}(\%)\end{array}$ & $\begin{array}{l}\text { Post-intervention } \\
\mathbf{n}(\%)\end{array}$ & $\begin{array}{l}\text { P-value } \\
\text { (McNemar's test)* }\end{array}$ \\
\hline Very good & $6(14.3)$ & $18(42.9)$ & $<0.00 \mathrm{I}$ \\
Good & $22(52.4)$ & $12(28.6)$ & \\
Fair & $14(33.3)$ & $12(28.6)$ & \\
Poor & 0 & 0 & \\
Very poor & 0 & 0 & \\
\hline
\end{tabular}

Note: *McNemar's test was used to determine within-subject changes in self-rated health (very good versus good + fair) from baseline to post-intervention.

and enhance their self-awareness of negative thoughts, thereby enabling them to manage and even reduce their stress levels. A recent study showed that elderly individuals (mean age 79 years) with positive age stereotypes were $44 \%$ more likely to recover from disability than those with negative age stereotypes. The authors suggested that positive age stereotypes may promote recovery from disability by limiting the cardiovascular response to stress, improving physical balance, enhancing self-efficacy, and increasing engagement in healthy behaviors. ${ }^{41}$ In addition, the basic traditional Shaolin mind-body exercises incorporated in the study intervention, including training in Dan Tian breathing, shoulder relaxation, and nasal massage, may also help to minimize the physiological response to stress. Subjects in our DMBI program reported feeling relaxed during and after practicing their mind-body exercises. This indicates that DMBI can elicit improvements in well-being similar to those achieved by stress management programs and other types of mind-body intervention.

Despite the beneficial effects on perceived psychological stress, DMBI did not significantly improve depressive symptoms, which is in contrast with our previous study in patients with depression. ${ }^{16}$ It is possible that the number of subjects with depression was small $(n=2)$, which reduced the statistical power of this analysis in demonstrating the effect of DMBI. It is also possible that our subjects had fairly mild depressive symptoms at baseline, and that the beneficial effects of the intervention might only be apparent in people with depression.

Apart from the encouraging effects on perceived psychological stress, our study also demonstrated significantly improved BP in subjects with moderate to high BP at baseline. The underlying mechanism for this is not clear, but may be similar to the effects of deep breathing exercises, which exert their BP-lowering effect by increasing the sensitivity of baroreflex (a homeostatic process that helps to maintain blood pressure). ${ }^{42}$ Device-guided slow breathing has been suggested as a nonpharmacological approach to the treatment of hypertension. ${ }^{43}$ Yoga and meditation, both of which incorporate slow and deep breathing techniques, have also been found to contribute to lowering of $\mathrm{BP}^{44}$ Thus, it is possible that training in Dan Tian breathing and shoulder relaxation as part of DMBI may slow the heart rate and lower BP via the above-mentioned mechanisms. The BP-lowering effect may also partly depend on the concomitant psychological relaxation and stress reduction induced by this intervention. A number of studies have suggested that stress reduction programs such as meditation ${ }^{45,46}$ and relaxation ${ }^{47}$ can reduce $\mathrm{BP}$ in both normotensive and hypertensive individuals. Our finding of positive effects on BP in this study lends further support to this observation.

In this study, we observed a significant increase in mean walking speed of $0.04 \mathrm{~m} / \mathrm{s}$ after intervention. Walking speed, a surrogate of physical fitness, decreases with age. ${ }^{48}$ This influences an individual's ability to perform activities of daily living, and has been demonstrated to be predictive of disability, hospitalization, and mortality. ${ }^{49}$ Multifactorial interdisciplinary intervention has been shown to improve walking speed in older people ${ }^{50}$ however, this involves high levels of participation resulting in burden, and therefore may not be a long-lasting strategy for most elderly people. Therefore, the contribution of DMBI may be connected not only with psychological relaxation, but also with an improvement in brain activity patterns, ${ }^{51}$ thus improving walking performance. It has been suggested that training that produces a relaxed and attentive mind will enhance the performance of individuals ${ }^{52}$ because it enables them to be less easily distracted, remain focused on task, and cope with stressful work demands in a relaxed and flexible manner.

The present study also found concurrent improvements in certain aspects of sleep quality, eg, reduced sleep disturbances. This finding is consistent with previous studies in Western countries reporting the beneficial effect of cognitive behavioral training on insomnia in older adults. ${ }^{53}$ In addition, some improvement of bowel/digestive problems was reported, ie, $36 \%$ of subjects had significant treatment-related improvement in these problems. Our present results are consistent with those of our previous randomized controlled trial in community-dwelling adults. ${ }^{15}$

An additional benefit of our intervention was a significant improvement in self-rated health, a complex variable that captures multiple dimensions of the relationship between physical health, psychological well-being, and social factors. Self-rated health has also been demonstrated to be a powerful predictor of morbidity (eg, functional disability and cardiovascular disease) as well as mortality. ${ }^{54-58}$ In the present 
study, over $30 \%$ of subjects reported having an improved level of health (from fair to good/from good to very good), even though some had reported a history of diabetes, hypertension, stroke, and depression. The underlying mechanism for this is not clear, but an improvement in fitness levels may play a role. ${ }^{59}$ In addition, positive psychology and empowerment may contribute to the underlying mechanism. An improved level of health has been shown to be positively associated with a person's perception of their power to bring about changes in their lives (such as increasing engagement in preventive practices) that would subsequently affect their health status. ${ }^{60}$ Therefore, our results provide evidence that DMBI can improve people's state of mind and their perception of health status, and support the notion that this intervention could enhance health in older adults.

Qualitative analyses of feedback from subjects suggest that this form of treatment was well received. On the oneitem forced choice question canvassing the acceptability of the treatment, $76 \%$ and $64 \%$ of subjects rated DMBI as helpful for enhancing their psychological and physical health, respectively. Further, compliance was good. Although there was no follow-up data collection for this study, we observed that most subjects continued to practice their mind--body exercises for up to one month after completion of the program.

The limitations of this pilot study include its small sample size, the lack of a control for the group effect of DMBI, and its limited generalizability. The lack of a control group may be a potential threat to the internal validity of our results, so they should be interpreted in light of this. Our study population was more highly educated and more physically active than the general elderly population in Hong Kong, so our findings cannot be generalized to those who are institutionalized, the frail elderly, or those with a lower education level. The number of subjects with depression was small, and limited the statistical power of this analysis in demonstrating the effectiveness of DMBI; however, this pilot study was not specifically powered to detect changes in all variables measured. Further studies are needed to address these methodological weaknesses, and should consider inclusion of clinical and institutional populations to investigate the applicability and effects of DMBI in more depth. Given our encouraging results regarding the health benefits of DMBI in apparently healthy older adults, a beneficial effect may be expected in frailer individuals, the institutionalized elderly, and or those with significant morbidity, eg, high BP, distress, or depression. In addition, certain biomarkers, such as blood lipid and glucose levels, may not be easy to modify. Therefore, longer follow-up studies would yield better results, given that it takes time for the benefits of such programs to become apparent in everyday life. However, our study has several notable strengths, including use of an expert DMBI practitioner to design a program specifically for older adults, a sex-balanced study sample, and the inclusion of multiple outcome variables.

In conclusion, our pilot study shows that 12 weeks of DMBI training is a promising alternative intervention for community-dwelling older adults. This program has considerable beneficial effects on psychological stress, BP, physical performance, and self-rated health. In addition, its oriental origin makes it culturally relevant to the elderly Chinese population. Given the simple and cost-effective nature of DMBI, the high adherence rate, and the encouraging results of this study, further investigation in the form of a randomized controlled trial is warranted to confirm the effects of this intervention.

\section{Acknowledgments}

This work was supported by the Health and Health Services Research Fund (grant number 10110931) established by the Food and Health Bureau of the Hong Kong SAR. The authors would like to specially thank Venerbale Master Dejian of the Songshan monastery for his teaching and support. They are also grateful to Ms Winnie Yeung, Mr Moses Wong, Ms Fannie Yeung, Ms Maggie Ng, Ms Karoline Chiu, Ms Hannah Li and Ms Carman Chu for their effort in subject recruitment, data collection/management/analysis, and/or literature review. Further appreciation is extended to all participants and to the community health and social centers (The Centre for Nutritional Studies, Jockey Club Centre for Osteoporosis Care and Control, Sheen Hok Charitable Foundation Kwan Shon Hing Yu Chui Neighbourhood Elderly Centre, Jockey Club CADENZA Hub, Ho Hong Neighbourhood Centre for Senior Citizens, and Heng On Social Centre for the Elderly) for their assistance in the recruitment process.

\section{Disclosure}

The authors report no conflicts of interest in this work.

\section{References}

1. Foley DJ, Monjan AA, Brown SL, Simonsick EM, Wallace RB, Blazer DG. Sleep complaints among elderly persons: an epidemiologic study of three communities. Sleep. 1995;18(6):425-432.

2. Spinzi G, Amato A, Imperiali G, et al. Constipation in the elderly: management strategies. Drugs Aging. 2009;26(6):469-474.

3. Caracciolo B, Backman L, Monastero R, Winblad B, Fratiglioni L. The symptom of low mood in the prodromal stage of mild cognitive impairment and dementia: a cohort study of a community dwelling elderly population. J Neurol Neurosurg Psychiatry. 2010;82(7): 788-793.

4. Auyeung TW, Kwok T, Lee J, Leung PC, Leung J, Woo J. Functional decline in cognitive impairment - the relationship between physical and cognitive function. Neuroepidemiology. 2008;31(3):167-173. 
5. UN Department of Economic and Social Affairs. World population ageing: 1950-2050. Available from: http://www.un.org/esa/population/ publications/worldageing19502050/. Accessed February 18, 2014.

6. Wang C, Bannuru R, Ramel J, Kupelnick B, Scott T, Schmid CH. Tai Chi on psychological well-being: systematic review and metaanalysis. BMC Complement Altern Med. 2010;10:23.

7. Lee MS, Pittler MH, Guo R, Ernst E. Qigong for hypertension: a systematic review of randomized clinical trials. J Hypertens. 2007;25(8): $1525-1532$.

8. Innes KE, Bourguignon C, Taylor AG. Risk indices associated with the insulin resistance syndrome, cardiovascular disease, and possible protection with yoga: a systematic review. $J$ Am Board Fam Pract. 2005;18(6):491-519.

9. Alexander C, Chandler H, Langer E, Newman R, Davies J. Transcendental meditation, mindfulness, and longevity: an experimental study with the elderly. J Pers Soc Psychol. 1989;57(6):950-964.

10. Leung DP, Chan CK, Tsang HW, Tsang WW, Jones AY. Tai chi as an intervention to improve balance and reduce falls in older adults: a systematic and meta-analytical review. Altern Ther Health Med. 2011;17(1):40-48

11. Lee MS, Lee EN, Kim JI, Ernst E. Tai chi for lowering resting blood pressure in the elderly: a systematic review. J Eval Clin Pract. 2010; 16(4):818-824.

12. Sjosten N, Vaapio S, Kivela SL. The effects of fall prevention trials on depressive symptoms and fear of falling among the aged: a systematic review. Aging Ment Health. 2008;12(1):30-46.

13. Tsang HW, Cheung L, Lak DC. Qigong as a psychosocial intervention for depressed elderly with chronic physical illnesses. Int J Geriatr Psychiatry. 2002;17(12):1146-1154.

14. Chan AS. Contemporary Application of Shaolin Medicine: Dejian Mind-Body Intervention. 5th ed. Hong Kong: Chanwuyi Publishing; 2013.

15. Chan AS, Cheung MC, Tsui WJ, Sze SL, Shi D. Dejian mind-body intervention on depressive mood of community-dwelling adults: a randomized controlled trial. Evid Based Complement Alternat Med. 2011;2011:473961.

16. Chan AS, Wong QY, Sze SL, Kwong PP, Han YM, Cheung MC. A Chinese Chan-based mind-body intervention for patients with depression. J Affect Disord. 2012;142(1-3):283-289.

17. Chan AS, Wong QY, Sze SL, Kwong PP, Han YM, Cheung MC A Chinese chan-based mind-body intervention improves sleep on patients with depression: a randomized controlled trial. ScientificWorldJournal. 2012;2012:235206.

18. Chan AS, Sze SL, Cheung MC, Lam JM, Shi D. Dejian mind-body intervention improves the functioning of a patient with chronic epilepsy: a case report. Cases J. 2009;2:9080.

19. Chan AS, Sze SL, Cheung MC, Han YM, Leung WW, Shi D. Dejian mind-body intervention improves the cognitive functions of a child with autism. Evid Based Complement Alternat Med. 2011;2011:549254.

20. Butland RJ, Pang J, Gross ER, Woodcock AA, Geddes DM. Two-, six-, and 12-minute walking tests in respiratory disease. $\mathrm{Br} \mathrm{Med} \mathrm{J}$ (Clin Res Ed). 1982;284(6329):1607-1608.

21. Yau CF. Cardiorespiratory Fitness of Hong Kong Chinese Elderly and its Relationship between Physical Activity Participation and Health. Shatin, Hong Kong: The Chinese University of Hong Kong; 2011.

22. Solway S, Brooks D, Lacasse Y, Thomas S. A qualitative systematic overview of the measurement properties of functional walk tests used in the cardiorespiratory domain. Chest. 2001;119(1):256-270.

23. Buysse DJ, Reynolds CF 3rd, Monk TH, Berman SR, Kupfer DJ. The Pittsburgh Sleep Quality Index: a new instrument for psychiatric practice and research. Psychiatry Res. 1989;28(2):193-213.

24. Tsai P, Wang S, Wang M, et al. Psychometric evaluation of the Chinese version of the Pittsburgh Sleep Quality Index (CPSQI) in primary insomnia and control subjects. Qual Life Res. 2005;14(8):1943-1952.

25. Buysse DJ, Reynolds CF, Monk TH, et al. Quantification of subjective sleep quality in healthy elderly men and women using the Pittsburgh Sleep Quality Index (PSQI). Sleep. 1991;14(4):331-338.
26. Motivala SJ, Levin MJ, Oxman MN, Irwin MR. Impairments in health functioning and sleep quality in older adults with a history of depression. J Am Geriatr Soc. 2006;54(8):1184-1191.

27. Chung KF, Tang MK. Subjective sleep disturbance and its correlates in middle-aged Hong Kong Chinese women. Maturitas. 2006;53(4):396-404.

28. Lai HL. Self-reported napping and nocturnal sleep in Taiwanese elderly insomniacs. Public Health Nurs. 2005;22(3):240-247.

29. Chan AO, Lam KF, Hui WM, et al. Validated questionnaire on diagnosis and symptom severity for functional constipation in the Chinese population. Aliment Pharmacol Ther. 2005;22(5):483-488.

30. Cohen S, Kamarck T, Mermelstein R. A global measure of perceived stress. J Health Soc Behav. 1983;24(4):385-396.

31. Yu RH, Ho SC. Psychometric evaluation of the perceived stress scale in early postmenopausal Chinese women. Psychology. 2010;1:1-8.

32. Lee HC, Chiu HF, Kowk WY, Leung CM, Kwong PK, Chung DW. Chinese elderly and the GDS short form: a preliminary study. Clin Gerontol. 1993;14(2):37-42.

33. Liu CY, Lu CH, Yu S, Yang YY. Correlations between scores on Chinese versions of long and short forms of the Geriatric Depression Scale among elderly Chinese. Psychol Rep. 1998;82(1):211-214.

34. Jacobson NS, Truax P. Clinical significance: a statistical approach to defining meaningful change in psychotherapy research. J Consult Clin Psychol. 1991;59(1):12-19.

35. Wise EA. Methods for analyzing psychotherapy outcomes: a review of clinical significance, reliable change, and recommendations for future directions. J Pers Assess. 2004;82(1):50-59.

36. American Heart Association. Understanding high blood pressure meaning. Available from: http://www.heart.org/HEARTORG/Conditions/ HighBloodPressure/AboutHighBloodPressure/Understanding-BloodPressure-Readings_UCM_301764_Article.jsp. Assessed January 31, 2014.

37. James PA, Oparil S, Carter BL, et al. 2014 Evidence-Based Guideline for the Management of High Blood Pressure in Adults: Report From the Panel Members Appointed to the Eighth Joint National Committee (JNC 8). JAMA. 2014;311(5):507-520.

38. Bulpitt CJ, Beckett NS, Cooke J, et al; Hypertension in the Very Elderly Trial Working Group. Results of the pilot study for the Hypertension in the Very Elderly Trial. J Hypertens. 2003;21(12):2409-2417.

39. Carmody J, Baer RA. Relationships between mindfulness practice and levels of mindfulness, medical and psychological symptoms and wellbeing in a mindfulness-based stress reduction program. J Behav Med. 2008;31(1):23-33.

40. Michalsen A, Grossman P, Acil A, et al. Rapid stress reduction and anxiolysis among distressed women as a consequence of a three-month intensive yoga program. Med Sci Monit. 2005;11(12):CR555-CR561.

41. Levy BR, Slade MD, Murphy TE, Gill TM. Association between positive age stereotypes and recovery from disability in older persons. JAMA. 2012;308(19):1972-1973.

42. Bernardi L, Spadacini G, Bellwon J, Hajric R, Roskamm H, Frey AW. Effect of breathing rate on oxygen saturation and exercise performance in chronic heart failure. Lancet. 1998;351(9112):1308-1311.

43. Parati G, Carretta R. Device-guided slow breathing as a nonpharmacological approach to antihypertensive treatment: efficacy, problems and perspectives. $J$ Hypertens. 2007;25(1):57-61.

44. Hughes JW, Fresco DM, Myerscough R, van Dulmen MH, Carlson LE, Josephson R. Randomized controlled trial of mindfulness-based stress reduction for prehypertension. Psychosom Med. 2013;75(8):721-728.

45. Rainforth MV, Schneider RH, Nidich SI, Gaylord-King C, Salerno JW, Anderson JW. Stress reduction programs in patients with elevated blood pressure: a systematic review and meta-analysis. Curr Hypertens Rep. 2007;9(6):520-528.

46. Schneider RH, Alexander CN, Staggers F, et al. A randomized controlled trial of stress reduction in African Americans treated for hypertension for over one year. Am J Hypertens. 2005;18(1): $88-98$. 
47. Dickinson H, Campbell F, Beyer F, et al. Relaxation therapies for the management of primary hypertension in adults: a Cochrane review. J Hum Hypertens. 2008;22(12):809-820.

48. Schimpl M, Moore C, Lederer C, et al. Association between walking speed and age in healthy, free-living individuals using mobile accelerometry-a cross-sectional study. PLoS One. 2011;6(8):e23299.

49. Dumurgier J, Elbaz A, Ducimetiere P, Tavernier B, Alperovitch A, Tzourio C. Slow walking speed and cardiovascular death in well functioning older adults: prospective cohort study. BMJ. 2009; 339:b4460.

50. Fairhall N, Sherrington C, Kurrle SE, Lord SR, Lockwood K, Cameron ID. Effect of a multifactorial interdisciplinary intervention on mobility-related disability in frail older people: randomised controlled trial. BMC Med. 2012;10:120.

51. Chan AS, Cheung MC, Sze SL, Leung WW, Shi D. Shaolin Dan Tian breathing fosters relaxed and attentive mind: a randomized controlled neuroelectrophysiological study. Evid Based Complement Alternat Med. 2011;2011:180704.

52. Vernon DJ. Can neurofeedback training enhance performance? An evaluation of the evidence with implications for future research. Appl Psychophysiol Biofeed. 2005;30(4):347-364.

53. Sivertsen B, Omvik S, Pallesen S, et al. Cognitive behavioral therapy vs zopiclone for treatment of chronic primary insomnia in older adults: a randomized controlled trial. JAMA. 2006;295(24):2851-2858.
54. Idler EL, Kasl SV. Self-ratings of health: do they also predict change in functional ability? J Gerontol B Psychol Sci Soc Sci. 1995;50(6): S344-S353.

55. van der Linde RM, Mavaddat N, Luben R, et al. Self-rated health and cardiovascular disease incidence: results from a longitudinal populationbased cohort in Norfolk, UK. PLoS One. 2013;8(6):e65290.

56. Badawi G, Page V, Smith KJ, et al. Self-rated health: a predictor for the three year incidence of major depression in individuals with type II diabetes. J Affect Disord. 2013;145(1):100-105.

57. Mossey JM, Shapiro E. Self-rated health: a predictor of mortality among the elderly. Am J Public Health. 1982;72(8):800-808.

58. Idler EL, BenyaminiY. Self-rated health and mortality: a review of twentyseven community studies. J Health Soc Behav. 1997;38(1):21-37.

59. Eriksen L, Curtis T, Grønbæk M, Helge JW, Tolstrup JS. The association between physical activity, cardiorespiratory fitness and self-rated health. Prev Med. 2013;57(6):900-902.

60. Bennett IM, Chen J, Soroui JS, White S. The contribution of health literacy to disparities in self-rated health status and preventive health behaviors in older adults. Ann Fam Med. 2009;7(3):204-211.
Clinical Interventions in Aging

\section{Publish your work in this journal}

Clinical Interventions in Aging is an international, peer-reviewed journal focusing on evidence-based reports on the value or lack thereof of treatments intended to prevent or delay the onset of maladaptive correlates of aging in human beings. This journal is indexed on PubMed Central, MedLine, the American Chemical Society's 'Chemical Abstracts Ser-

\section{Dovepress}

vice' (CAS), Scopus and the Elsevier Bibliographic databases. The manuscript management system is completely online and includes a very quick and fair peer-review system, which is all easy to use. Visit $\mathrm{http}: / /$ www.dovepress.com/testimonials.php to read real quotes from published authors. 